\title{
WAVEFORM DISCRIMINATION IN THE ELECTRIC FISH EIGENMANNIA: SENSITIVITY FOR THE PHASE DIFFERENCES BETWEEN THE SPECTRAL COMPONENTS OF A STIMULUS WAVE
}

\author{
BY BERND KRAMER AND BRUNHILDE OTTO \\ Zoological Institute of the University, D-8400 Regensburg, Federal Republic of \\ Germany
}

Accepted 4 April 1991

\begin{abstract}
Summary
Eigenmannia lineata is a tropical South American gymnotiform fish that is both electrogenic and electroreceptive. Its electric organ generates a constant-frequency wave discharge (EOD) that is sexually dimorphic in waveform and harmonic content. Eigenmannia discriminates digitally synthesized, natural male and female EOD waveforms of identical frequency and amplitude. Experiments were devised to investigate behaviourally the sensory mechanism of this discrimination.

Both the content in higher harmonics (as seen in an amplitude spectrum) and the waveform (phase spectrum) could provide the cues Eigenmannia uses for discrimination. Five Eigenmannia were trained to discriminate artificially generated stimuli composed of the fundamental frequency, $f_{1}$, and its harmonic, $f_{2}$, of a frequency twice that of $f_{1}$ and of weaker intensity $\left(-13\right.$ to $-3 \mathrm{~dB}$ re $f_{1}$; a similar variation is found among the EODs of different Eigenmannia individuals). The rewarded stimulus, $\mathrm{S}+$ (with a strong $f_{2}$ intensity of $-3 \mathrm{~dB}$ re $f_{1}$ ), remained constant throughout the experiments. The family of negative $(\mathrm{S}-$ ) stimuli all had a phase difference of $0^{\circ}$, that is, no phase difference, between their harmonics, while the $\mathrm{S}+$ stimulus had a phase difference of $90^{\circ}$. Therefore, all $\mathrm{S}-$ stimuli differed from the $S+$ stimulus in waveform, while one $S-$ stimulus had an amplitude spectrum identical to that of the $S+$ stimulus.

All fish discriminated any $S-$ signal tested from the $S+$ stimulus, including the $S-$ stimulus with an identical amplitude spectrum, both when the test signals had identical energy contents (that is, slightly different peak-to-peak amplitudes) and when they had identical peak-to-peak amplitudes (hence, slightly different energy contents).

These results are evidence for a true waveform (time domain) sensitivity of Eigenmannia. A sensory mechanism is proposed that enables Eigenmannia to assess the $P / N$ ratio of a wave signal, that is, the duration ratio of positive $(P)$ and negative $(\mathrm{N})$ half-waves between zero-crossings of a stimulus cycle (the $\mathrm{S}+$ and all $\mathrm{S}-$ stimuli, as well as female and male EODs, differ in this regard).
\end{abstract}

Key words: electrosensory, electroreception, signal waveform, phase difference, amplitude spectrum, sexual dimorphism, Eigenmannia. 
A stimulus modulates a fish's own discharge, or 'carrier' frequency, in amplitude and phase at the difference (or beat) frequency. These modulations show characteristic differences depending on the stimulus waveform; they also differ in relative phase for the right and left sides of the body, or for the head and for the tail, by $180^{\circ}$ (half a beat cycle). Between the right and left body sides, the relative phase modulation of zero-crossings is shown to reflect the waveform of a stimulus on a greatly expanded time scale (a beat cycle).

The proposed mechanism relies on (1) the T-type electroreceptors (phase or time coders); (2) a fast, time-preserving electrosensory pathway in the brain; and (3) a recently described time-measuring neuronal circuit in the mesencephalon.

\section{Introduction}

Eigenmannia lineata is a weakly electric, teleost fish from tropical South America (Sternopygidae, Gymnotiformes) that possesses a complex electrosensorimotor system for nocturnal communication and active object location (Lissmann, 1958; reviews collated in Bullock and Heiligenberg, 1986; reviews by Kramer, 1990a,b). Its electric organ discharge (EOD) is a continuous wave, usually with a constant frequency within a species range of approximately $240-600 \mathrm{~Hz}$ at $27^{\circ} \mathrm{C}$ (Lissmann, 1958). Male and female discharges differ in waveform: females display an almost sinusoidal discharge low in harmonic content, while the waveform of male discharges is more asymmetrical (both in amplitude and in time) and high in harmonic content (Fig. 1).

Trained fish discriminated digitally synthesized, 'natural' male from female discharges played back by a dipole, even when there was no difference in amplitude and fundamental frequency (Kramer and Zupanc, 1986). Furthermore, untrained (naïve) fish preferred to move towards, and stay close to, a dipole playing back synthetic female discharges rather than towards one playing male discharges, even though the identical dipoles bore no resemblance to a real fish (except in their dimensions and horizontal orientation, as well as the spatial geometry and amplitude of the artificial electric fields). The preference for artificial female EODs was observed in fish of both sexes, in both adults and juveniles (Kramer and Otto, 1988).

The sensory mechanism of this discrimination is not clear. The tuberous electroreceptors (those that respond to the fish's own and other fishes' discharges) have $V$-shaped tuning curves, with their 'best' frequencies at EOD frequency (Scheich et al. 1973; Hopkins, 1976; for a recent review, see Zakon, 1988). Behavioural threshold estimations using sine-wave stimuli also confirmed that a stimulus wave is bandpass-filtered, with the pass-band narrowly centred on a fish's individual EOD frequency (its fundamental frequency, or $f_{1}$, component; Knudsen, 1974). Therefore, minimum attenuation is expected for a fish's own EOD frequency, while higher or lower frequencies should increasingly be suppressed the more they differ from the EOD frequency (an attenuation of approximately $20 \mathrm{~dB}$ per octave or more on the 'high' side of the 'best' frequency, as determined by both behavioural and electrophysiological techniques; reviewed by Kramer, 

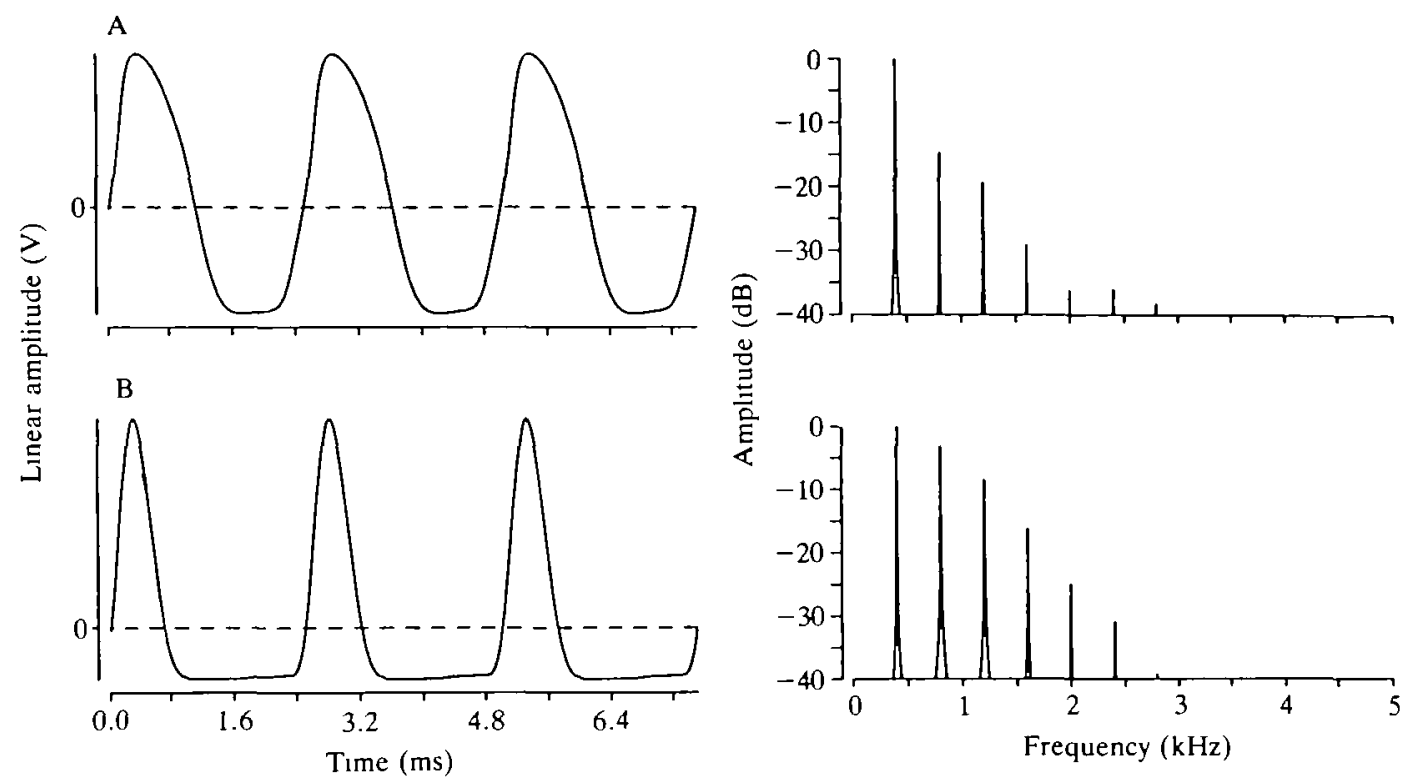

Fig. 1. Waveforms (left) of female (A) and male (B) discharges of Eigenmannia with their associated amplitude spectra (right). Note the almost sinusoidal waveform and low harmonic content, or low intensity of overtones, in the female discharge (A), while the male discharge (B) contains strong overtones (that is, integer multiples of the fundamental frequency). The ordinate in the amplitude spectra shows amplitude in decibels relative to the strongest spectral component (of $0 \mathrm{~dB}$ attenuation).

1985). This type of signal processing can also be called 'spectral line filtering'; a frequency-domain concept.

Using a variety of complex stimulus waveforms, including synthesized male and female EODs, spectral line filtering (at a fish's individual EOD frequency) was indeed shown to underlie the jamming avoidance response (JAR; Kramer, 1985). (The JAR, as first observed by Watanabe and Takeda, 1963, and studied in more detail by Bullock et al. 1972, is an EOD frequency shift away from a weak a.c. signal sufficiently close to a fish's EOD frequency; although other types of frequency modulation, including no and 'wrong' responses, may also occur; Kramer, 1987, 1990a,b). However, spectral line filtering could not explain the categorical discrimination by the fishes of sine from sawtooth waves even when their fundamental frequency components, which were near EOD frequency, were of identical intensities (Kramer and Zupanc, 1986). (These stimuli would give JARs of identical strength; Kramer, 1985.)

An alternative type of signal analysis that might better explain the fishes' capacity for discriminating different waveforms, such as male from female EODs, as separate categories, is based on the pattern of zero-crossing intervals of the stimulus waves (a time-domain concept; for example, the ' $\mathrm{P} / \mathrm{N}$ ratio' of Gottschalk, 1981). In the juvenile and female EOD, the duration of the head-positive (P) part of an EOD cycle is almost equal to the head-negative $(\mathrm{N})$ part, resulting in 
high $\mathrm{P} / \mathrm{N}$ ratios close to, but always below, 1 . In the adult male $\mathrm{EOD}$, however, the head-negative part is often more than twice the duration of the head-positive part (resulting in $\mathrm{P} / \mathrm{N}$ ratios of around 0.5 or even as low as 0.4 ; Kramer, 1985).

T-receptors sense the times of zero-crossings of the complex wave (one spike per cycle) that result from the superposition of the fish's own electric field on that of the stimulus and the phase modulation within a beat cycle (Scheich and Bullock, 1974; Scheich, 1974, 1977a,b,c; see review by Heiligenberg, 1988). However, this does not afford sensitivity for the $\mathrm{P} / \mathrm{N}$ ratio, because $\mathrm{T}$-receptors do not follow the rapid alternation of positive- and negative-going zero-crossings at twice EOD frequency.

Fish discriminate different waveforms of identical $\mathrm{P} / \mathrm{N}$ ratio, such as the sine wave from the sawtooth wave, even when their $f_{1}$ intensities are identical (as mentioned above). Therefore, differences in the pattern of zero-crossing intervals in a stimulus wave are not required for categorical discrimination of different waveforms when they differ in spectral amplitudes.

In Kramer and Zupanc's (1986) study, pairs of signals discriminated by trained fish differed in two ways: (1) in the number and intensity of overtones, or higher harmonics, that collectively determine the 'timbre' of a signal (by analogy with an acoustic signal); (2) in the phase relationships of overtones (if present). Therefore, in the present study we chose stimuli that only differed in waveform, but not in spectral amplitudes. We assumed that the fish, like the human ear receiving acoustic signals (excluding very low frequencies), would be unable to sense a 'pure' difference in phase relationship among the harmonics that constitute a signal, provided that there are no further cues. However, Eigenmannia did detect such phase differences between the overtones of a stimulus wave.

\section{Materials and methods}

We used five Eigenmannia (Sternopygus) lineata Müller and Troschel (Sternopygidae, Gymnotiformes, Teleostei) (deposited in the Zoologische Staatssammlung, Munich, ZSM 27156-27160). Their individual characteristics are given in Table 1.

Table 1. Individual characteristics of the test fish used (fish no. 4: second measurement 4 months after the first)

\begin{tabular}{lccccc}
\hline & \multicolumn{5}{c}{ Fish number } \\
\cline { 2 - 6 } & 1 & 2 & 3 & 4 & 5 \\
\hline Length $(\mathrm{cm})$ & 14.5 & 14.0 & 11.0 & 13.0 & 15.0 \\
& & & & 13.5 & \\
P/N ratio & 0.87 & 0.65 & 0.81 & 0.64 & 0.67
\end{tabular}

Sex unknown, as it could only have been determined by killing the fish. 


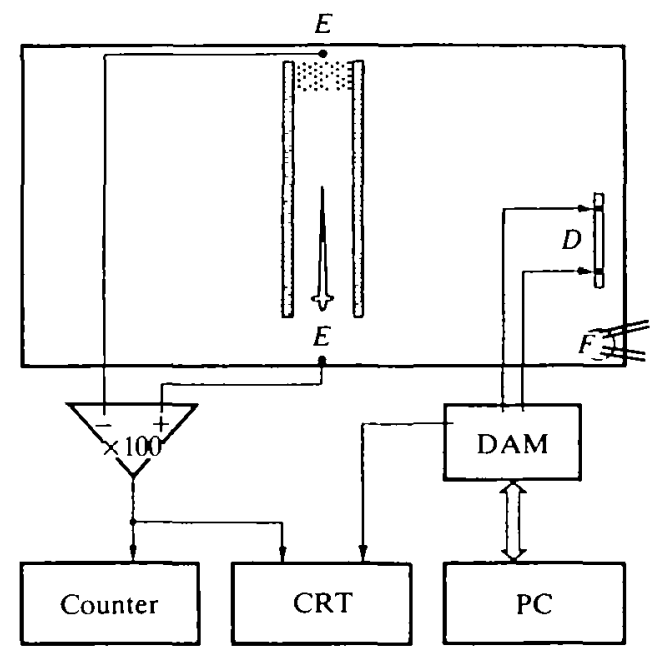

Fig. 2. Schematic representation of the experimental apparatus used for conditioned discrimination experiments, with the fish resting in its porous pot. DAM, microprocessor-controlled stimulus generator connected to a dipole $D ; F$, feeding station, a Petri dish, with one tube for injecting a food reward, the other for 'punishing' wrong responses with a few air bubbles; CRT, oscilloscope; PC, computer. Electric organ discharges were picked up by carbon electrodes $(E)$ and differentially amplified $(\times 100$; $10 \mathrm{~Hz}-100 \mathrm{kHz}$ ). The discharge frequency was measured by a universal counter.

Experiments were conducted in a $120-1$ aquarium $(75 \mathrm{~cm} \times 40 \mathrm{~cm} \times 42 \mathrm{~cm}$ high); water conductivity, $100 \pm 5 \mu \mathrm{S} \mathrm{cm}^{-1}$; temperature, $27 \pm 1^{\circ} \mathrm{C}$. The water was filtered and aerated. All fish used a porous pot shelter (outer and inner diameters, 10.0 and $7.5 \mathrm{~cm}$, respectively) during the day, when experiments were conducted (L:D, $12 \mathrm{~h}: 12 \mathrm{~h}$ ). Owing to the shyness of most fish, light intensity was subdued, depending on the individual (from 50 to $320 \mathrm{~lx}$, measured under water with the probe on the aquarium floor).

The porous pot was in the rear centre of the aquarium, with its long axis $(32.5 \mathrm{~cm}$ ) parallel to the smaller sides (Fig. 2). During the day, fish hovered, stationary, inside the pot, with their heads near the opening facing the observer, while the rear opening was obstructed by 'Java moss' (Vesicularia dubyana, Hypnobryales) and touched the rear aquarium wall. A glass Petri dish (inner diameter, $5.5 \mathrm{~cm}$; rim height, $1 \mathrm{~cm}$ ) in the front right-hand corner of the aquarium (with respect to the observer) served as a feeding station where the reward, a single Chironomus (bloodworm) larva, or punishment, a few air bubbles, was delivered. The Chironomus larvae were freshly prepared from a frozen supply. Single larvae were injected into the Petri dish by hydrostatic pressure, via a manually operated syringe/plastic tube arrangement that ended with a vertical glass tube (inner diameter, $2 \mathrm{~mm}$; outer diameter, $4 \mathrm{~mm}$ ). An identical arrangement was used in parallel with that just described for punishment with air bubbles.

Immediately before each experiment, the test fish's EOD frequency was 
measured with a resolution of $\pm 1 \mathrm{~Hz}$ (Hewlett Packard model 5314A universal counter). The stimulus frequency was $50 \mathrm{~Hz}$ above EOD frequency, in order not to evoke a JAR.

Stimuli were presented via a dipole near the Petri dish. The dipole imitated the electric field generated by a medium-sized female Eigenmannia. The dipole consisted of two vertically oriented carbon rod electrodes (rod diameter, $0.5 \mathrm{~cm}$; length, $1 \mathrm{~cm}$; separation, $7.8 \mathrm{~cm}$ ) fixed in the lateral holes of a horizontally oriented acrylic tube (outer diameter, $1.2 \mathrm{~cm}$; length, $12 \mathrm{~cm}$ ) containing the leads connecting the generator output to the carbon rod electrodes. All openings were sealed with transparent silicone rubber. The upper edge of the acrylic tube was $4 \mathrm{~cm}$ above the aquarium bottom, with the carbon rod electrodes projecting upwards. The dipole was oriented parallel to the smaller sides of the aquarium and the porous pot shelter, from the centre of which it was separated by $30 \mathrm{~cm}$ (that is, the fish's resting position).

The stimulus waves were composed of the fundamental frequency (or first harmonic), $f_{1}$, and its second harmonic, $f_{2}$, of variable amplitude and phase difference relative to $f_{1}$, calculated as:

$$
y=\sin \omega t+a \sin (2 \omega t+\phi)
$$

where $\omega=2 \pi f, f$ is frequency, $t$ is time, $a$ is amplitude and $\phi$ is phase difference.

The rewarded signal, S+ (designated $\phi 90-3$ ) had a $90^{\circ}$ phase difference between its constituent two harmonics, $f_{1}$ and $f_{2}$, and remained constant throughout all experiments. The series of $\mathrm{S}-$ stimuli had no, or $0^{\circ}$, phase difference between their harmonics ( $\phi 0-13$ to $\phi 0-3$; Fig. 3 ). These $S-$ signals differed among each other only by the intensities of their second harmonics, $f_{2}$, which ranged from -13 to $-3 \mathrm{~dB}$ relative to their $f_{1}$ components (Table 2). The amplitude spectrum of one $S-$ stimulus, the $\phi 0-3$ signal, was identical to that of the $\mathrm{S}+$ stimulus, but the difference in phase relationship between the harmonics of the two signals was $90^{\circ}$ (that is, the maximum possible difference; $180^{\circ}$ being identical to the $0^{\circ}$ waveform inverted). A strong second harmonic of $-3 \mathrm{~dB}$ was also found in the EOD of large Eigenmannia males (Kramer, 1985).

The computer-generated data were transferred to a microprocessor-controlled digital-to-analogue converter with memory (Kramer and Weymann, 1987). A host computer, operated by the experimenter, gave the instructions necessary to select a waveform and to start and stop the stimulation. Stimulus rise and fall time was $400 \mathrm{~ms}$. A sine wave of $270 \mu \mathrm{V}_{\mathrm{p}-\mathrm{p}} \mathrm{cm}^{-1}$ at the resting position of the fish (measured

Fig. 3. (A-G) Stimulus signals. Left, waveforms, as displayed on an oscilloscope (ordinate, linear amplitude in volts); right, the associated amplitude spectra, showing the relative attenuation of the second harmonic, $f_{2}$, compared to the stronger fundamental frequency component, $f_{1}$. Amplitude is expressed in decibels. A-F are all $\mathrm{S}-$ stimuli, with a phase difference of $0^{\circ}$ between their $f_{1}$ and $f_{2}$ harmonics; $\mathrm{G}$ is the $\mathrm{S}+$ stimulus, with a phase difference of $90^{\circ}$. (A) S - with an $f_{2}$ intensity of $-13 \mathrm{~dB}$ re $f_{1} ;$ (B) S - with an $f_{2}$ of $-8 \mathrm{~dB}$ re $f_{1}$; (C) S- with an $f_{2}$ of $-6 \mathrm{~dB}$ re $f_{1}$; (D) S- with an $f_{2}$ of $-5 \mathrm{~dB}$ re $f_{1}$; (E) S- with an $f_{2}$ of $-4 \mathrm{~dB}$ re $f_{1}$; (F) S- with an $f_{2}$ of $-3 \mathrm{~dB}$ re $f_{1}$; (G) S+ with an $f_{2}$ of $-3 \mathrm{~dB}$ re $f_{1}$. 
Electrosensory waveform discrimination

7
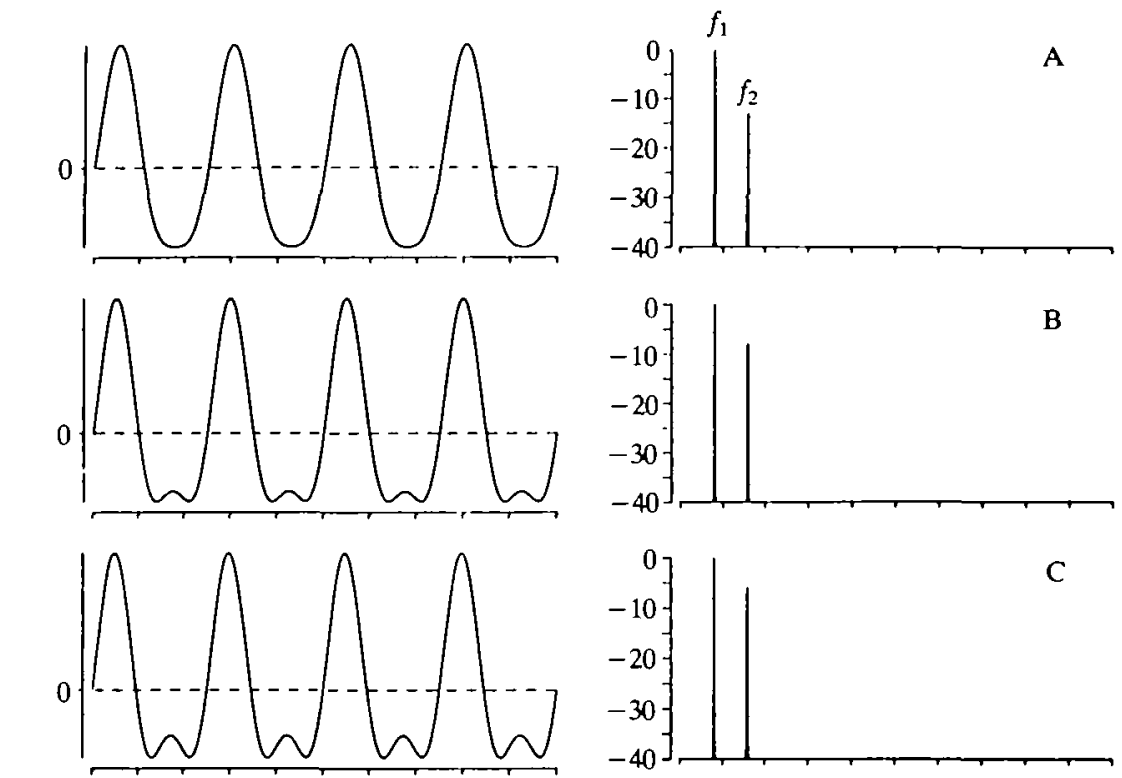

C
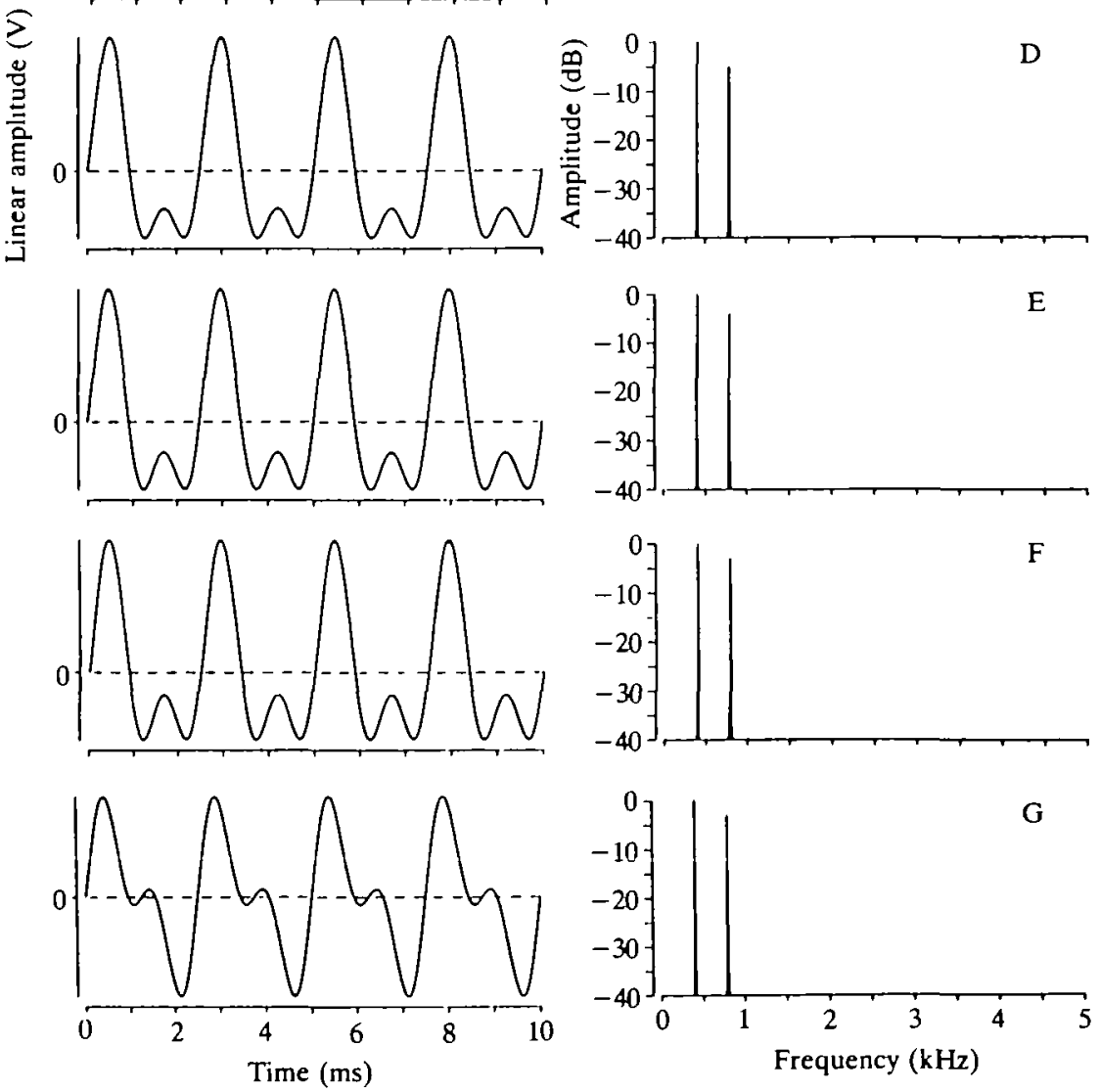

Fig. 3 
Table 2. Relative intensity relationships among the stimuli used, composed of a fundamental frequency, $\mathrm{f}_{1}$, and its second harmonic, $\mathrm{f}_{2}$

\begin{tabular}{lcccc}
\hline Stimulus & $\begin{array}{c}f_{1} \\
\text { intensity }\end{array}$ & $\begin{array}{c}f_{2} \text { intensity } \\
\text { re } f_{1}(\mathrm{~dB})\end{array}$ & $\begin{array}{c}\text { Amplitude } \\
\text { peak-to-peak }\end{array}$ & $\begin{array}{c}\text { Amplitude } \\
\text { r.m.s. }\end{array}$ \\
\hline Sine & 1.00 & $\begin{array}{c}\text { Below detection } \\
\text { limit }\end{array}$ & 1.00 & 1.00 \\
S+ $(\phi \mathbf{9 0 - 3 )}$ & 1.00 & -3.0 & 1.495 & 1.22 \\
S- $(\phi 0-3)$ & 1.00 & -3.0 & 1.31 & 1.22 \\
S- $\phi 0-4$ & 1.00 & -4.0 & 1.22 & 1.17 \\
$S-\phi 0-5$ & 1.00 & -5.0 & 1.19 & 1.15 \\
$S-\phi 0-6$ & 1.00 & -6.0 & 1.125 & 1.11 \\
$S-\phi 0-8$ & 1.00 & -8.0 & 1.07 & 1.07 \\
$S-\phi 0-13$ & 1.00 & -13.1 & 1.01 & 1.02
\end{tabular}

A sine wave of $270 \mu \mathrm{V}_{\mathrm{p}-\mathrm{p}} \mathrm{cm}^{-1}$ at the fish's resting position was the reference intensity for the $f_{1}$ component.

Note that these signals of equal $f_{1}$ intensities differed in peak-to-peak amplitude even when of equal energy contents, as shown by the amplitude root mean square (r.m.s.) measurements for the $S+$ and the $S-$ signals (bold type).

with the fish and its shelter removed), at $30 \mathrm{~cm}$ distance from the dipole, was the reference intensity for the fundamental frequency component of stimulus waves. This intensity was $43 \mathrm{~dB}$ above threshold of the conditioned response (threshold, $2 \mu \mathrm{V}_{\mathrm{p}-\mathrm{p}} \mathrm{cm}^{-1}$; I. Kaunzinger and B. Kramer, unpublished results).

An oscilloscope was used for peak-to-peak amplitude measurements and a Brüel \& Kjær measuring amplifier (type 2610) was used for root mean square (r.m.s.) measurements. The intensity relationships of the $f_{1}$ and $f_{2}$ components of the signals were determined (1) by Fourier amplitude spectrum analysis of a waveform sample of 1024 data points digitized at $12 \mathrm{bit} / 10 \mathrm{kHz}$; (2) by using an electronic filter (Wavetek/Rockland model 452) as a low-pass for determining $f_{1}$ intensities and as a high-pass for determining $f_{2}$ intensities. These were read off the screen of the oscilloscope or the meter of the Brüel \& Kjær measuring amplifier. For $f_{1}$ measurements, the cut-off frequency of the filter was set to $f_{1}$, while it was set to $f_{2}$ for determining the intensity of the $f_{2}$ component (roll-off, $48 \mathrm{~dB} /$ octave).

Beat patterns of artificially generated, 'natural' female and male EODs were obtained by electronically mixing the outputs from two of the devices designed for digitally synthesizing natural EODs with high fidelity (Kramer and Weymann, 1987). Concurrent beat patterns for addition and subtraction were recorded using the two channels of a $20 \mathrm{MHz}$, eight-bit digital storage oscilloscope $(2 \times 4096$ points; Philips DSO model 3335). The frequencies chosen were $400 \mathrm{~Hz}$ for the artificial female EOD of full $(100 \%)$ amplitude, and $450 \mathrm{~Hz}$ for the artificial male or female EODs of $30 \%$ amplitude (which were added to or subtracted from the signal of full amplitude). The data stored in the oscilloscope were transferred to a computer and beat patterns were analyzed and plotted.

A fish's basic training began by forming the association 'electric stimulus (a sine 

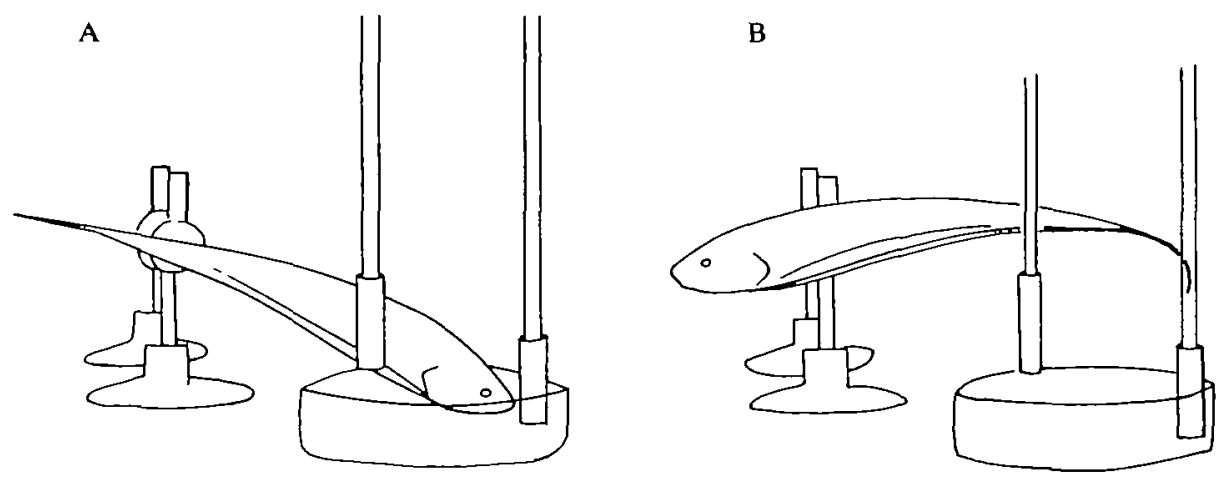

Fig. 4. (A) A trained Eigenmannia taking its food reward on being presented with the rewarded stimulus, S+. Fish typically approach the feeding station in one smooth, quick swimming bout and take their reward from the tube. (B) Behaviour displayed on presentation of the $\mathrm{S}$ - signal. Although fish may, as shown here, approach the feeding station with little hesitation (similar to the response to the $\mathrm{S}+$ stimulation), they often swim backwards while doing so; they stop some distance from the Petri dish, and swim rapidly away. During the first visit (if there is more than one), no attempt is made to put the head into the feeding station; this may occur only much later during the same session. Redrawn from video recordings.

wave) on' with a food reward, obtained at the Petri dish (sine wave, $270 \mu \mathrm{V}_{\mathrm{p}-\mathrm{p}} \mathrm{cm}^{-1}$ at the fish's shelter; $50 \mathrm{~Hz}$ above EOD frequency). A correct response was recorded as the time ('latency') between stimulus onset and the fish taking a bloodworm in its mouth from the reward tube (Fig. 4A). In order to do this, the fish had to swim from its shelter to the Petri dish, because stimulation was never started when the fish was not hiding.

On successful completion of this learning task, discrimination conditioning began by using two stimuli, $\mathrm{S}+$ and $\mathrm{S}-$, associated with either reward or mild punishment, respectively. An incorrect response was recorded when the fish moved its head over the rim of the Petri dish with the S- signal on. An incorrect response was immediately punished by a few air bubbles delivered through the second tube (Fig. 4B); this chased the fish away. When a reward or punishment was delivered the stimulus was turned off immediately.

The sequence of $\mathrm{S}+$ and $\mathrm{S}-$ signals followed a randomized blocks design (Cochran and Cox, 1968). A block consisted of 20 trials; every fifth trial was a 'test' trial with neither reward nor punishment. Within a block, 'training' and 'test' trials of both kinds, $\mathrm{S}+$ and $\mathrm{S}-$, were presented equally often, but permuted in random order using Table 15.7 of Cochran and Cox (1968). No permutation of that Table was used twice for a fish. Permutations that had the same stimulus more than three times in a row were not used.

When a fish did not respond, the stimulus was turned off after $120 \mathrm{~s}$. The minimum interval between trials was $3 \mathrm{~min}$ in discrimination conditioning. During basic training, an interval of $3 \mathrm{~min}$ was added to the number of spots on a dice 
times $30 \mathrm{~s}$ (that is, the inter-trial interval varied from 3.5 to $6 \mathrm{~min}$ ). Therefore, fish could not use the principle of an egg timer in predicting the next reward.

For statistical analyses the Mann-Whitney $U$-test was used (Siegel, 1956).

\section{Results}

Basic training, that is the association of a stimulus signal presented by the dipole with a food reward at the feeding station, was usually achieved within the first session. On stimulus onset, a trained fish would swim smoothly to the feeding station and take its reward from the opening of the reward tube (Fig. 4A).

Between training sessions, when the stimulus was turned off, fish regularly checked the feeding station for food. However, response latencies to 'real' stimulation were significantly shorter than those to 'fictitious' stimulation (with an identical experimental procedure except that the 'signal-on' button was not pressed by the experimenter, although he moved his hand; hence, there was no signal on the electrodes). The response latencies to real stimuli ranged from 4.8 to $18.5 \mathrm{~s}$ (overall means for different fish; Fig. 5), while for fictitious stimuli they averaged $33.8-108 \mathrm{~s}$.

After successful completion of the basic training, discrimination conditioning started. First, an S- signal was chosen that had, in addition to the different phase relationship of its constituent harmonics, a much weaker $f_{2}$ component compared to that of the $\mathrm{S}+$ signal. In fish no. 1 the first $\mathrm{S}$ - signal used was $\phi 0-13$, which was the most dissimilar signal compared to the $\mathrm{S}+$ signal used in the present study (the $f_{2}$ was $-13 \mathrm{~dB}$ re $f_{1}$ ). This was found unnecessary in the other four fish, where the first $S-$ signal used was $\phi 0-8$, which is more similar to the $S+$ signal in its much stronger $f_{2}$ component (an $f_{2}$ of $-8 \mathrm{~dB}$ re $f_{1}$ ).

All fish clearly discriminated these $\mathrm{S}-$ signals from the $\mathrm{S}+$ signal (Table 3 ). For the next experiment an $\mathrm{S}-$ signal of stronger $f_{2}$ component was used in each fish. When the new pair of signals was also discriminated, the $f_{2}$ intensity of the $\mathrm{S}$ signal was raised again, and so on (in steps of $+1 \mathrm{~dB}$ ).

All $\mathrm{S}$ - signals that differed in their $f_{2}$ intensity from that of the $\mathrm{S}+$ were successfully discriminated, even when the intensity difference was only $1 \mathrm{~dB}$ (stimulus $\phi 0-4$ with an $f_{2}$ that was $4 \mathrm{~dB}$ weaker than its own $f_{1}$, was discriminated from the $\mathrm{S}+$ signal with its $f_{2}$ of $-3 \mathrm{~dB}$; see Table 3 ).

Therefore, for the next experiment an $S$ - signal with an amplitude spectrum identical to that of the $S+$ signal, in which there were no intensity differences of the $f_{2}$ components, was used. In these cases, the different phase relationships between the constituent harmonics of the signals, translating into different waveforms, were the only possible cues for discrimination (see Fig. 3). Unexpectedly, all five fish discriminated these signals of identical amplitude spectra but different waveform (Table 3; Fig. 6A). This was shown by much shorter response latencies to the $S+$ (averaging less than $10 \mathrm{~s}$ in each fish) compared to the $\mathrm{S}$ signal; that is, similar values to those obtained during basic training tests when no S- signal was used (see Fig. 5). 


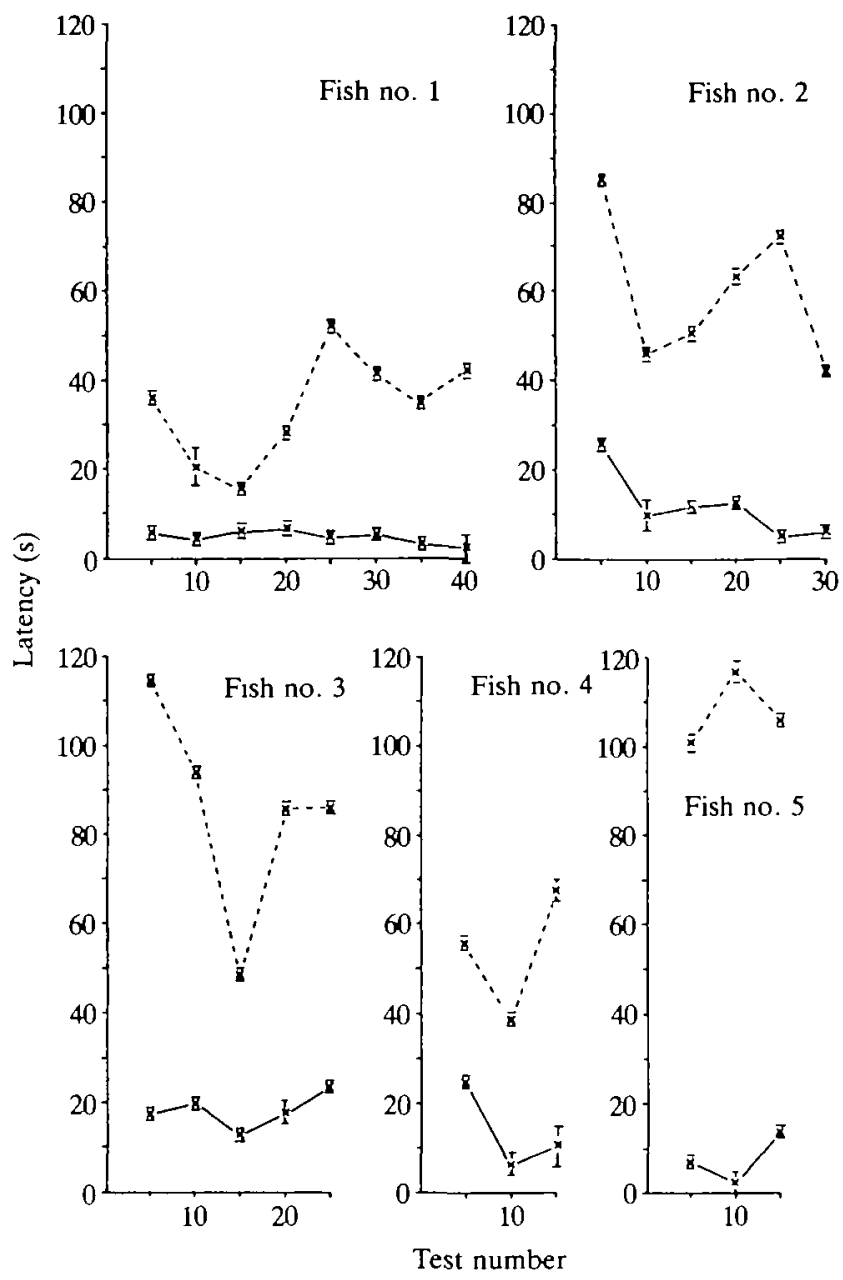

Fig. 5. Response latencies to 'real' (solid lines) and 'fictitious' (broken lines) stimulation, that is pseudo-stimulation or no stimulation, for each fish. For fictitious stimulation, the experimenter behaved as if he were about to deliver a stimulus (without pressing the button). The ordinate is the time between the stimulus onset (real or fictitious) and the fish investigating the feeding station for food. Even without electrical stimulation, fish eventually investigate the feeding station from time to time, as shown by the results with fictitious stimulation. Note, however, that electric stimulation via the dipole summons the fish much earlier to the feeding station compared to pseudo-stimulation (that is, visual/mechanical stimulation by the experimenter's movements preparatory to stimulation). Each point is the mean of five test experiments \pm S.E. (no training experiments included). In each fish, the two populations of data are significantly different $(P<0.001$; Mann-Whitney $U$-test).

Could this discrimination performance be due to cues other than phase differences in harmonics, which are the reason for the waveform differences? There is one possibility left. 
Table 3. Response latencies of fish to $S+$ and $S-$ signals

\begin{tabular}{|c|c|c|c|c|c|}
\hline \multirow[b]{2}{*}{ Stimulus } & \multicolumn{5}{|c|}{ Response latency (s) } \\
\hline & Fish no. 1 & Fish no. 2 & Fish no. 3 & Fish no. 4 & Fish no. 5 \\
\hline $\mathrm{S}+(\phi 90-3)$ & $11.3 \pm 23.69$ & & & & \\
\hline$S-(\phi 0-13)$ & $\begin{array}{c}67.4 \pm 9.4 \\
N=24 \\
z=-4.732\end{array}$ & & & & \\
\hline $\mathrm{S}+(\phi 90-3)$ & $6.7 \pm 1.18$ & $15.1 \pm 1.71$ & $35.4 \pm 10.45$ & & $8.7 \pm 1.26$ \\
\hline$S-(\phi 0-8)$ & $\begin{array}{c}63.4 \pm 8.85 \\
N=24 \\
z=-5.753\end{array}$ & $\begin{array}{c}79.8 \pm 10.37 \\
N=16 \\
U=12\end{array}$ & $\begin{array}{c}92.7 \pm 8.46 \\
N=14 \\
U=26\end{array}$ & & $\begin{array}{c}112.6 \pm 5.55 \\
N=8 \\
U=0\end{array}$ \\
\hline$S+(\phi 90-3)$ & $10.5 \pm 2.20$ & $8.2 \pm 2.44$ & $6.8 \pm 0.80$ & $23.2 \pm 6.59$ & $4.7 \pm 0.56$ \\
\hline$S-(\phi 0-6)$ & $\begin{array}{c}102.0 \pm 5.43 \\
N=32 \\
z=-6.646\end{array}$ & $\begin{array}{c}68.9 \pm 8.13 \\
N=12 \\
U=2\end{array}$ & $\begin{array}{c}92.2 \pm 14.04 \\
N=10 \\
U=0\end{array}$ & $\begin{array}{c}66.6 \pm 12.28 \\
N=10 \\
U=16^{*}\end{array}$ & $\begin{array}{c}44.4 \pm 13.14 \\
N=8 \\
U=0\end{array}$ \\
\hline $\mathrm{S}+(\phi 90-3)$ & $9.1 \pm 3.14$ & $4.8 \pm 0.31$ & & & \\
\hline$S-(\phi 0-5)$ & $\begin{array}{c}75.0 \pm 8.63 \\
N=28 \\
z=-5.801\end{array}$ & $\begin{array}{c}92.0 \pm 11.11 \\
N=6 \\
U=0\end{array}$ & & & \\
\hline$S+(\phi 90-3)$ & $10.4 \pm 3.23$ & & $5.9 \pm 0.31$ & $11.3 \pm 3.14$ & $10.2 \pm 2.30$ \\
\hline$S-(\phi 0-4)$ & $\begin{array}{c}76.0 \pm 8.08 \\
N=36 \\
z=-5.772\end{array}$ & & $\begin{array}{c}114.1 \pm 5.90 \\
N=10 \\
U=0\end{array}$ & $\begin{array}{c}56.7 \pm 13.03 \\
N=10 \\
U=7.5\end{array}$ & $\begin{array}{c}51.9 \pm 11.82 \\
N=10 \\
U=2\end{array}$ \\
\hline$S+(\phi 90-3)$ & $8.4 \pm 1.68$ & $4.1 \pm 0.29$ & $6.8 \pm 0.76$ & $8.2 \pm 3.01$ & $8.1 \pm 2.23$ \\
\hline$S-(\phi 0-3)$ & $\begin{array}{c}113.1 \pm 4.82 \\
N=24 \\
z=-5.794\end{array}$ & $\begin{array}{c}92.0 \pm 7.19 \\
N=12 \\
U=0\end{array}$ & $\begin{array}{c}109.0 \pm 7.35 \\
N=10 \\
U=0\end{array}$ & $\begin{array}{c}70.5 \pm 15.03 \\
N=10 \\
U=3.5\end{array}$ & $\begin{array}{c}31.5 \pm 9.89 \\
N=12 \\
U=20\end{array}$ \\
\hline
\end{tabular}

Sequence of experiments, from top to bottom. Some $S+/ S-$ pairings were skipped in individual fish (except the bottom line pair).

Note that each fish learned to discriminate each pair of $\mathrm{S}+$ and $\mathrm{S}-$ signals; especially the $S+/ S-$ pair with identical Fourier amplitude spectra, but different waveform (bottom pair, bold type).

$P<0.001$ in each case, except * where $P<0.01$. $P$ values were obtained from a Mann-Whitney $U$-test; based either on the $U$-statistic or on $z$, the standard normal deviate (depending on $N$, the sample size for each one of the means per set).

All S- signals tested up to now had an $f_{1}$ component of identical absolute strength to that of the S+ signal. Therefore, the overall energy content of an Ssignal varied according to the relative strength of its $f_{2}$ component (see Table 2); only the S- signal used in Fig. 6A was identical to the S+ signal both in terms of relative spectral amplitude (as shown in Fig. 3) and in total energy content. Because of the different phase relationships between the constituent harmonics of the $\mathrm{S}+$ and the $\mathrm{S}-$ signals, their peak-to-peak amplitudes necessarily differed (Table 2). We therefore examined the possibility that the fish could have discriminated the stimuli (as used for Fig. 6A) by their difference in peak-to-peak amplitudes rather than in harmonic phase relationships. 
A

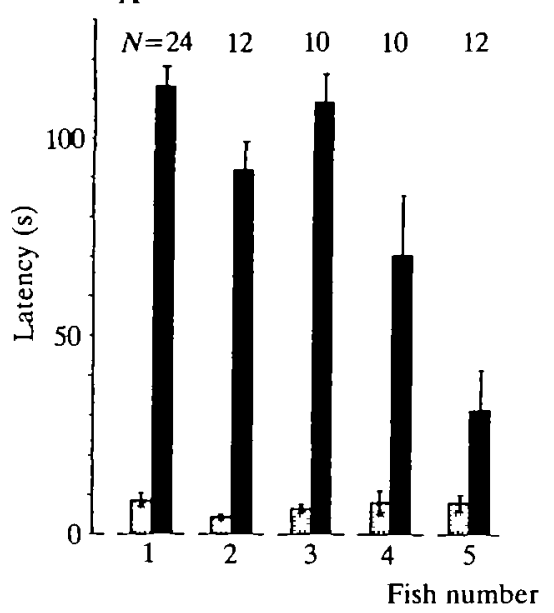

B

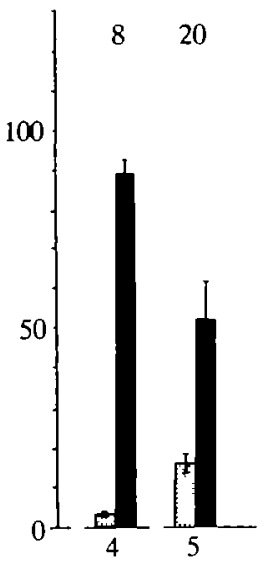

Fig. 6. (A,B) Response latencies in test experiments to stimuli of identical amplitude spectra, but differing in the phase relationship of their constituent harmonic components. Stippled columns, latencies to the $S+$ signal; filled columns, latencies to the $\mathrm{S}-$ signal. (A) The $\mathrm{S}+$ and the $\mathrm{S}-$ signals had identical energy contents; hence, different peak-to-peak amplitudes $(\phi 90-3$ and $\phi 0-3$ of Table 2). All fish discriminated the signals. (B) The $S+$ and the $S-$ signals were of equal peak-to-peak amplitude during the test experiments (which are shown here), but not during training presentations of the signals ( $\phi 90-3$ and $\phi 0-3$ of Table 4). Note the significantly shorter response latencies to the $S+$ signal, compared with those to the $S-$ signal, in both $\mathrm{A}$ and $\mathrm{B}$.

This was tested in two of the five fish previously tested. Discrimination conditioning was exactly the same as that used for Fig. $6 \mathrm{~A}$; that is, the $\mathrm{S}-$ signal was of identical energy content to the $\mathrm{S}+$ signal; hence, of different peak-to-peak amplitude (see Table 2). However, for the test experiments the intensity of the $\mathrm{S}-$ signal was reduced such that it exactly matched the peak-to-peak amplitude of the S+ signal (hence, different energy contents; Table 4). Thus, should fish have discriminated the stimuli by their difference in peak-to-peak amplitude during training sessions, they could no longer do so during the rarer test experiments. As shown in Fig. 6B, fish still discriminated the $S+$ from the $S-$ signal, in spite of the lack of a peak-to-peak amplitude difference.

When looking for a possible sensory mechanism for this discrimination (see Discussion), the beat pattern of the two fields that mix in the water (resulting from the superposition of the fish's own field with that of the stimulus) should be considered, since it is this that a local electroreceptor will detect. Two effects of the superposition have been identified using artificial stimulus fields: amplitude and phase modulation (Scheich, 1977a,b,c; see review by Heiligenberg, 1988).

For the present purpose, the superposition of artificially generated, 'natural' EODs was studied (those of Fig. 1); both for subtraction and addition of fields. As explained below (see Discussion and Fig. 9), addition and subtraction correspond 
Table 4. Relative intensity relationships of the $S+$ and $S-$ signals, of identical amplitude spectra but different waveforms, as used for the experiment of Fig. $6 B$ (test presentations)

\begin{tabular}{lcccc}
\hline Stimulus & $\begin{array}{c}f_{1} \\
\text { intensity }\end{array}$ & $\begin{array}{c}f_{2} \text { intensity } \\
\text { re } f_{1}(\mathrm{~dB})\end{array}$ & $\begin{array}{c}\text { Amplitude } \\
\text { peak-to-peak }\end{array}$ & $\begin{array}{c}\text { Amplitude } \\
\text { r.m.s. }\end{array}$ \\
\hline $\mathrm{S}+(\phi 90-3)$ & 0.87 & -3.0 & 1.31 & 1.08 \\
$\mathrm{~S}-(\phi 0-3)$ & 1.00 & -3.0 & 1.31 & 1.22 \\
Sine & 1.00 & below detection & 1.00 & 1.00 \\
& \multicolumn{4}{c}{ limit }
\end{tabular}

Note that the $\mathrm{S}+$ and the $\mathrm{S}-$ signals were of equal peak-to-peak amplitude, hence different energy contents (as shown by amplitude root mean square measurements), during test presentations only, while during training presentations the energy contents of the $\mathrm{S}+$ and the $\mathrm{S}-$ signals were kept identical (hence their peak-to-peak amplitudes were different, as shown in Table 2). Otherwise details as in Table 2.

to the superposition fields to which the local electroreceptors of the left and right sides of the fish will be exposed when a conspecific comes sufficiently close.

As a stimulus field, a male or female EOD of $450 \mathrm{~Hz}$ and $30 \%$ amplitude was electronically added to, or subtracted from, a female EOD of $100 \%$ amplitude (which was considered to be the fish's 'own' discharge of $400 \mathrm{~Hz}$ ). At the chosen frequency difference of $50 \mathrm{~Hz}$, the duration of a beat cycle was $20 \mathrm{~ms}$ (or eight cycles of the stronger EOD; Fig. 7). The amplitude modulation of the stronger EOD shows characteristic differences for the two stimulus waveforms used; furthermore, the beat patterns for addition and subtraction differ in phase by half a beat cycle (Fig. 7).

When the stimulus is a female EOD, the modulation of the phase difference of zero-crossings between the addition and the subtraction fields follows a smooth, almost sinusoidal, time course (Fig. 8A). Within a beat cycle of (in this example) $20 \mathrm{~ms}$, the positive-going zero-crossings of the field resulting from an addition lag increasingly behind those of the alternative superposition field, up to a maximum of about $150 \mu \mathrm{s}$. At the amplitude maximum, the phase difference becomes zero; the phase difference, now of reversed sign, increases again up to a maximum of about $250 \mu \mathrm{s}$ (it is now the zero-crossings of the subtraction field that lag in phase). Phase differences are highest at about one-quarter and three-quarters of a beat cycle (corresponding to about half the amplitude modulation depth).

When the stimulus is a male EOD, phase differences between zero-crossings of the two superposition fields are relatively weak (about $70 \mu \mathrm{s}$ ) for the greater part of a beat cycle, but briefly reach very high values (200-250 $\mu$ s; Fig. 8B). Different amplitude relationships between the two waveforms that are mixed would yield different absolute phase differences; the shape of the phase difference function, however, would be unaffected.

In summary, the modulation of phase differences of zero-crossings between the addition and the subtraction superposition fields shows characteristic differences, 


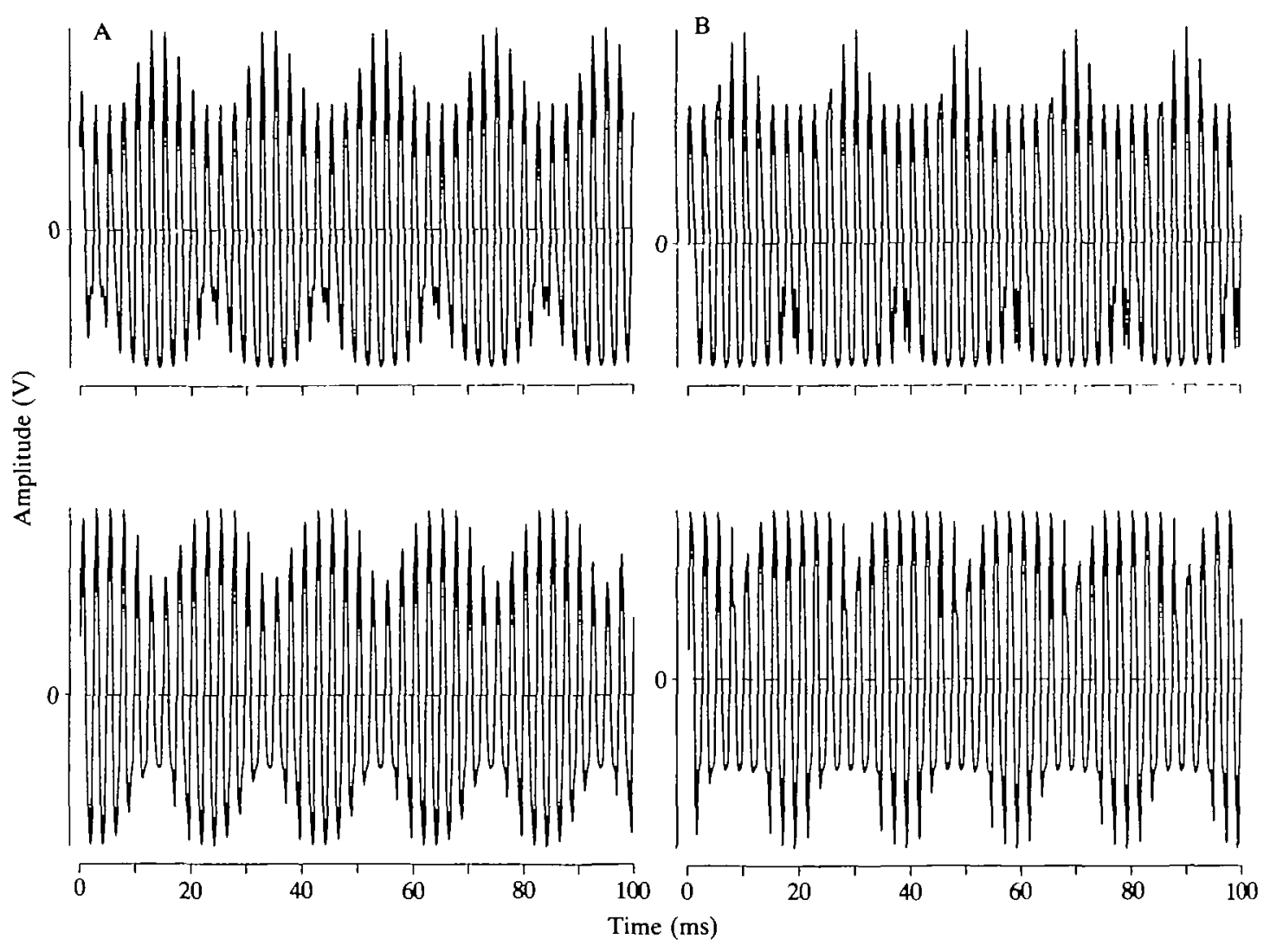

Fig. 7. (A,B) Superposition of electronically generated electric organ discharges (EODs) of two Eigenmannia. A strong female EOD of $100 \%$ amplitude and $400 \mathrm{~Hz}$ is considered to be the fish's 'own' field and is mixed with a 'stimulus' EOD of $30 \%$ amplitude and $450 \mathrm{~Hz}$ (female in A, male in B). Top traces in A and B result from an addition of fields, bottom traces from a subtraction of the weaker from the stronger field. Note (1) that the beat patterns for addition and subtraction show a phase difference of half a beat cycle, and (2) that the stronger EOD is amplitude-modulated in characteristic fashion, depending on the 'stimulus' waveform. The duration of a beat cycle is $20 \mathrm{~ms}$ in this example.

depending on the stimulus waveform that is being superimposed on a fish's own discharge. The relative phase modulation reflects the original waveform of the stimulus on a greatly expanded time scale: while the individual $\mathrm{P} / \mathrm{N}$ ratios of the female and male EOD waveforms, as used in Fig. 8, were 0.82 and 0.40 , respectively, the estimates of the $\mathrm{P} / \mathrm{N}$ ratios from the phase modulation per beat cycle are 0.78 and 0.44 . These estimates would be more exact at a smaller difference frequency, because of increased resolution of sampling.

\section{Discussion}

In earlier studies it was shown that Eigenmannia discriminates the sexually 

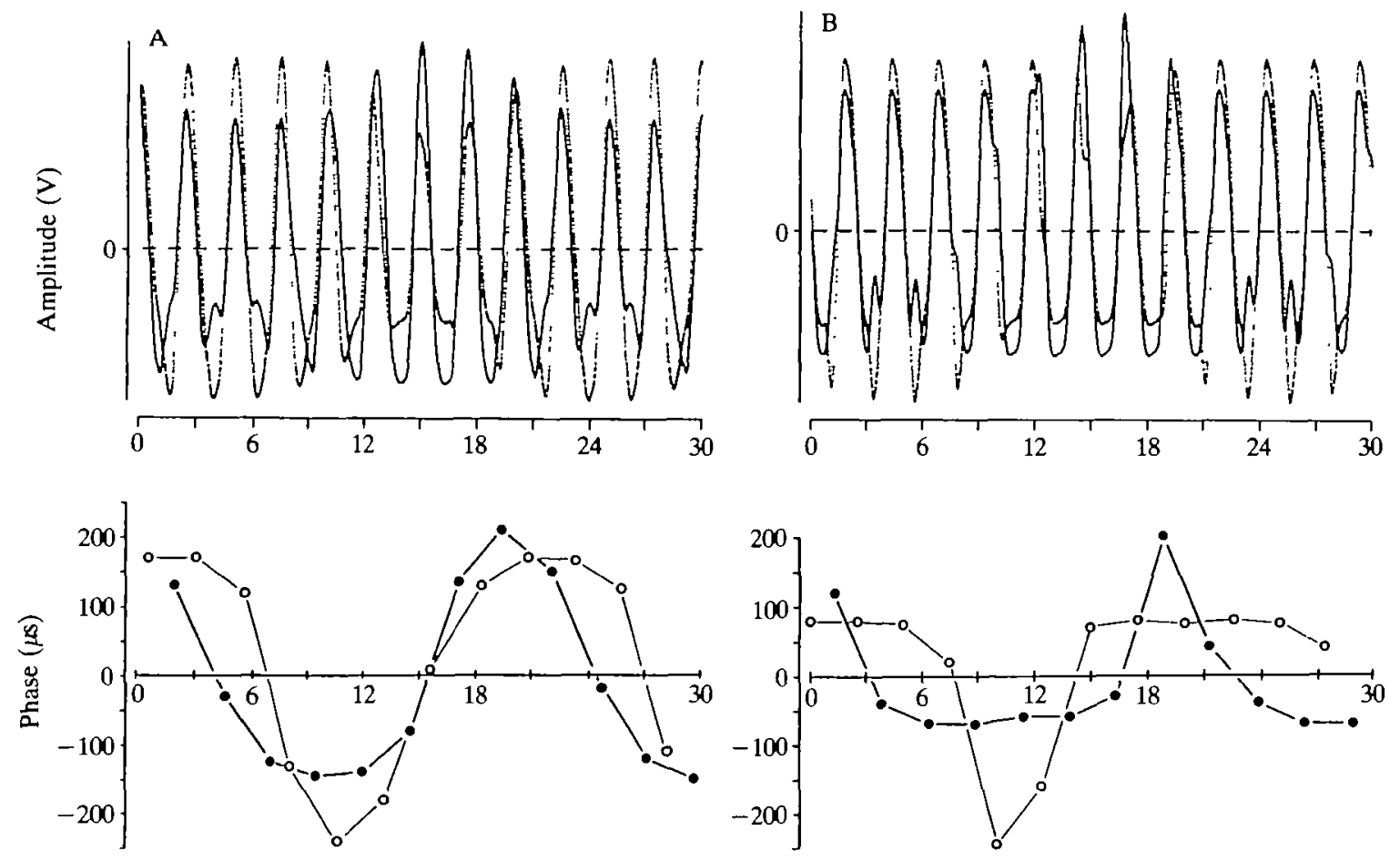

Time (ms)

Fig. 8. (A,B) Electronically generated beat pattern of a female electric organ discharge (EOD; of $400 \mathrm{~Hz}$ ) superimposed on a weaker conspecific discharge (of $30 \%$ amplitude, $450 \mathrm{~Hz}$ ). Superimposed on a strong female EOD is a weaker female EOD in $\mathrm{A}$, and a weaker male EOD in B. (A,B) Top, the superposition fields resulting from waveform addition are indicated by the solid line, those from waveform subtraction by the dotted line. The duration of a beat cycle is $20 \mathrm{~ms}$, one full beat cycle for waveform addition is shown in the centre of each graph. $(A, B)$ Bottom, the concurrent phase differences of zero-crossings between the two superposition fields are shown for positive-going zero-crossings $(O)$ and negative-going zero-crossings $(O)$. Note that phase differences of up to $250 \mu \mathrm{s}$ occur (or one-tenth of one cycle of the 'carrier' frequency); the time course of this phase modulation reflects the waveform of the stimulus: almost sinusoidal for a female stimulus (A), more asymmetrical for a male stimulus (B).

dimorphic EOD waveform of conspecifics, and other waveforms; that is, signals that differed in both waveform and harmonic content (Kramer and Zupanc, 1986; Kramer and Otto, 1988; see Introduction). The present results clearly show that Eigenmannia discriminates signals that differ only in waveform, but are identical in spectral amplitudes (or timbre in the case of an acoustic signal). The difference in waveform resulted from a shift in phase between the constituent harmonics of a periodic function. This unique type of phase sensitivity affords obvious advantages to a wave-type electric fish. Another kind of phase sensitivity, sensitivity to the polarity of stimulus pulses, has been demonstrated in pulse gymnotiforms. 
(Heiligenberg and Altes, 1978; Westby, 1974; see also discussion in Kramer, 1985, pp. 63-64).

With this phase sensitivity, fish should be able not only to discriminate between different individuals of their own species on the basis of their EOD waveforms (as shown experimentally; Kramer and Zupanc, 1986; Kramer and Otto, 1988) but also to recognize conspecific EODs from those of most other species by their characteristic differences in waveform (see Kramer et al. 1981; Kramer, 1990b). Alternative mechanisms, such as species recognition by fundamental frequency, are insufficient, because the species-characteristic frequency range of Eigenmannia lineata is partially or totally overlapped by those of many other species (Kramer et al. 1981). Nor is the harmonic content of EODs sufficient for species recognition, because this varies widely among different individuals of Eigenmannia lineata (Kramer, 1985). However, sensitivity to the waveform of a signal should enable a fish to recognize a conspecific EOD from most, if not all, wave EODs of other genera within its frequency range. Within the genus Eigenmannia, however, EOD waveforms might sometimes be too similar for discrimination. This question cannot be properly addressed at present because the taxonomy of the genus is unclear (F. Mago-Leccia, personal communication).

A sensory mechanism for the discrimination of different waveforms of identical harmonic content, compatible with the present and earlier data, might rely on the differences in $\mathrm{P} / \mathrm{N}$ ratio of the stimulus waves, because one waveform used in the present experiments, the $\mathrm{S}+$ signal, is time-symmetrical with identical zerocrossing intervals for the $\mathrm{P}$ and $\mathrm{N}$ half-waves (that is, $\mathrm{P} / \mathrm{N}=1$ if we disregard the two mini-peaks caused by the second harmonic; Fig. 3G); the alternative Sstimulus had a $\mathrm{P} / \mathrm{N}$ ratio of only 0.56 (Fig. 3F).

Fish receive a T-receptor response that is phase-locked to the positive-going zero-crossing of its EOD (one afferent spike per EOD cycle; Scheich et al. 1973; see review by Zakon, 1986). Because the current generated by the electric organ flows from inside to outside, all receptors (left and right side) are stimulated in phase (that is, give synchronous responses; Fig. 9A).

The electric field from another fish, however, stimulates the left- and right-side receptors with opposite polarity. (This was also observed for African mormyrids discharging in irregularly spaced pulses, inviting the hypothesis that these fishes may discriminate stimulus pulses of different durations; Hopkins and Bass, 1981; but see discussion in Kramer, 1985, pp. 63-64.) Therefore, if we disregard for a moment the fish's own EOD, the responses of the left- and right-side receptors to the stimulus wave, if above threshold, alternate (Fig. 9B). (This should be the real situation at about the middle of the electric organ where the zero isopotential line of the fish's field crosses its body.) The difference interval between positive-going zero-crossings for the left and right sides is exactly half of the stimulus cycle for a sine wave, since its $\mathrm{P} / \mathrm{N}$ ratio is 1 (that is, a phase shift of T-receptor responses right versus left of $180^{\circ}$ ). The pair of difference intervals for one stimulus cycle become slightly asymmetrical (short-long pattern) for a female or juvenile EOD, and very markedly so for a male EOD. 

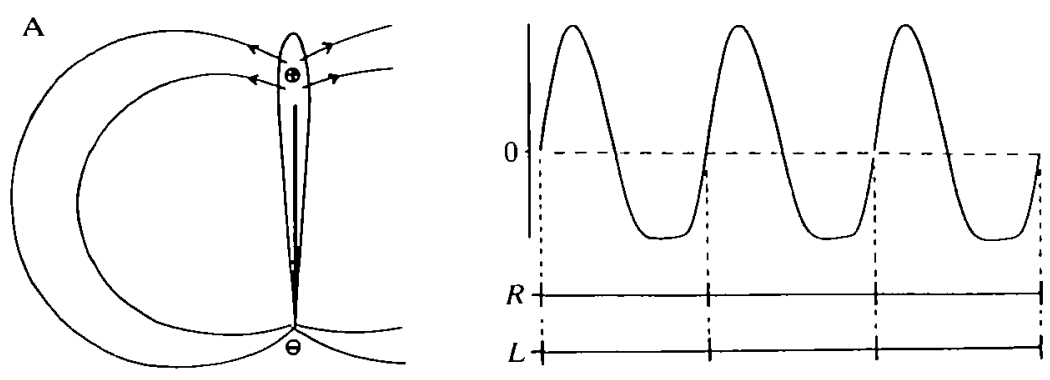

B
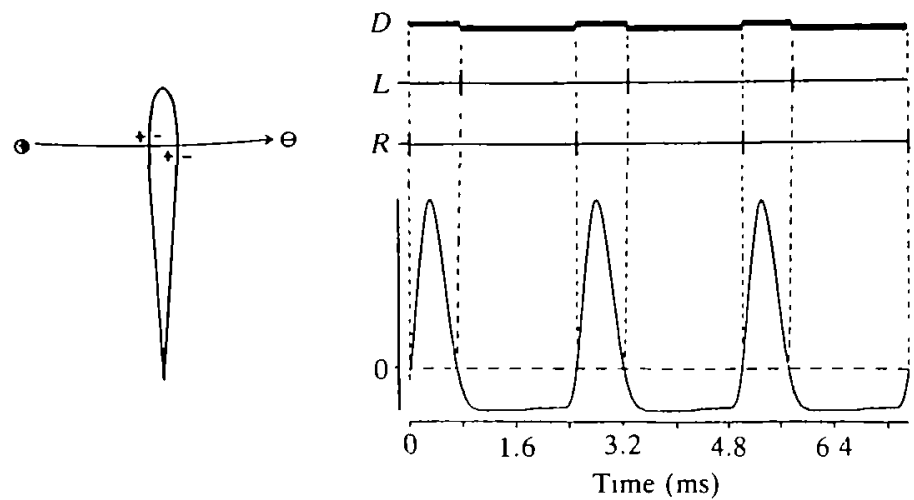

Fig. 9. (A,B) Schematic representation of T-electroreceptor responses to electric organ discharges (EOD). (A) Response to a fish's own discharge; (B) response to another fish's discharges. (A) Left, the fish's electric organ is shown as a dipole bar; current flows from inside to outside (only two current lines are shown). The potential across the skin has the same polarity on both sides of the body at any one moment. Right, tuberous $T$-receptors in the skin mark the positive-going zero-crossings of the discharge by one spike; all T-receptors fire in phase. (B) Left, the electric current from another fish (a male in this example) flows through the body by stimulating left- and right-side receptors with opposite polarities (a $180^{\circ}$ difference in stimulus phase left $v s$ right). Right, if, for clarity, the fish's own discharge is disregarded and the stimulus is above threshold, the pattern of right- and left-side T-receptor responses will depend on the $\mathrm{P} / \mathrm{N}$ ratio of the stimulus (or ratio of zero-crossing intervals for positive and negative half-waves of a cycle). For example, there will be a short-long pattern of difference intervals $(D)$ between the T-receptor afferences of the left and the right side for a male waveform, as shown. In most body areas the stimulus field (B, left) will be relatively weak, modulating the fish's own strong discharge (A, left) by advancing or delaying the zero-crossings of the combined local field relative to those of the fish's uncontaminated discharge (see Figs 7,8 ). However, where the zero isopotential line crosses the fish's body near the middle of the schematic dipole bar, the total transepidermal voltage gradient is determined by the stimulus alone, as shown in $\mathrm{B} . R$, right; $L$, left.

At the majority of local receptors, however, the stimulus field will be weaker than the fish's own strong EOD, and will modulate the fish's electric field in amplitude and phase; that is, advance or delay the zero-crossings of the combined 
field relative to those of the fish's uncontaminated EOD, depending on the relative strengths and geometry of local fields, on the frequency difference and on the relative phase. The degree of these amplitude and phase modulations varies for different body parts, because of different amplitude ratios of the EOD and stimulus. By evaluating the differential phase between different body parts, the fish can compute reference information about the phase of its own EOD (reviewed by Heiligenberg, 1988). Fish detect a phase modulation of their EOD in the range of $1 \mu$ s (Rose and Heiligenberg, 1985).

A weak stimulus field superimposed on the fish's own strong EOD yields beat patterns that are different for the fish's left and right body sides (since one results from addition of the two fields, the other from subtraction of the weaker from the stronger field; Fig. 9). If the stimulus field is of $30 \%$ amplitude compared to the fish's own field, the depth of the phase modulation of the combined fields (left versus right) reaches the remarkable value of up to $250 \mu$ s (or one-tenth of a cycle of the fish's EOD in this example using 'natural', synthesized EOD waveforms; Fig. 8). This is more than 600 times the threshold given by Rose and Heiligenberg (1985).

In monitoring the difference between the arrival times of left- and right-side T-receptor responses, the fish should be able to detect the characteristically different phase modulation of its own EOD for different stimulus waveforms. For example, if the stimulus is a female EOD, the time course of the left versus right phase modulation is almost sinusoidal (as is the waveform of the stimulus itself), while a male EOD stimulus causes an asymmetrical phase modulation with a time course resembling that of a male EOD waveform (Fig. 8). Therefore, the stimulus waveform (volts over time) appears to be transposed into phase modulation over time, on a greatly expanded time scale. At a difference frequency of $50 \mathrm{~Hz}$ (as used here), the duration of a beat cycle is only $20 \mathrm{~ms}$ (or eight EOD cycles in this example); therefore, scanning the stimulus waveform by sampling the phase modulation of the combined field is very crude. However, at a frequency difference of $4 \mathrm{~Hz}$ (as is often observed after a jamming avoidance response), a fish discharging at $400 \mathrm{~Hz}$ will be able to scan the stimulus waveform for a beat cycle of $250 \mathrm{~ms}$, or 100 EOD cycles, with greatly improved resolution.

A neuronal circuit capable of computing phase differences between the T-receptor afferences from different body parts is needed for the suggested sensory mechanism. Unlike the situation in mormyrids (Bell, 1989), such a circuit has indeed been described by Carr et al. (1986) for Eigenmannia; it is part of Szabo's (1967; p. 97 in Szabo and Fessard, 1974) type I 'fast' electrosensory system. It involves the spherical cells of the electrosensory lateral line lobe (ELL, of the medulla) that project onto the somata of giant cells and the dendrites of small cells of layer 6 of the torus semicircularis (of the mesencephalon). The small cells also receive input from distant giant cells and can thus compute differential phase between $T$ afferences from different body regions. The projections of the $T$ afferences within the central nervous system are specialized for preserving precise 
timing relative to the EOD, although they do not appear to maintain detailed spatial information (reviewed by Bell, 1989).

This circuit has been characterized as an essential element for the jamming avoidance response, where differential phase information is needed to determine the sign of the difference frequency between stimulus and EOD (reviewed by Heiligenberg, 1988). There is no reason why the circuit should not also (or perhaps normally) analyse stimulus waveform. For the present purpose, the function of the circuit would be clearest if it were capable of computing the phase between leftand right-side T-receptor afferences (or those between head and tail). Although not yet experimentally confirmed, this seems possible on neuroanatomical grounds. The spherical cells of the ELL project to the contralateral side of a somatotopical map of the body in the torus semicircularis; giant cells distribute phase information to the vicinity of their contralateral homologues, and other cells to rostral and caudal areas of the torus (reviewed by Carr, 1990). Therefore, a left/right side (or head/tail) comparison of the phase of T-afferences might occur at the level of the small cells of layer 6 of the torus.

The discrimination of constant-frequency waveforms is a new sensory function for an acoustico-lateral line receptor system; it is achieved without any accessory or transducing structures ahead of the receptor cells that might help to analyze the signal, and probably involves extensive central nervous analysis of sensory information.

This work was supported by the Deutsche Forschungsgemeinschaft (SFB4, grant $\mathrm{H} 1$ to B.K.). We would like to thank Drs D. Burkhardt and G. von der Emde and two anonymous referees for critically discussing the manuscript, as well as the assistant editor, Y. Z. Erzinclioglu, for his most careful editing of the manuscript.

\section{References}

BELL, C. C. (1989). Sensory coding and corollary discharge effects in mormyrid electric fish. J. exp. Biol. 146, 229-253.

Bullock, T. H., Hamstra, R. H. And Scheich, H. (1972). The jamming avoidance response of high frequency electric fish. J. comp. Physiol. 77, 1-48.

Bullock, T. H. ANd Heiligenberg, W. (1986) (eds). Electroreception. New York: John Wiley \& Sons, Inc.

CARr, C. E. (1990). Neuroethology of electric fish. Principles of coding and processing sensory information. BioScience 40, 259-267.

CARr, C. E., Maler, L. AND Taylor, B. (1986). A time-comparison circuit in the electric fish midbrain. II. Functional morphology. J. Neurosci. 6, 1372-1383.

Cochran, W. G. and Cox, G. M. (1968). Experimental Designs. New York: John Wiley \& Sons, Inc.

Gotrschalk, B. (1981). Electrocommunication in gymnotid wave fish: significance of a temporal feature in the electric organ discharge. In. Sensory Physiology of Aquatic Lower Vertebrates, Adv. physiol. Sci. 31 (ed. T. Szabo and G. Czeh), pp. 255-277. Budapest: Pergamon Press/Akademiai Kiado.

Heiligenterg, W. (1988). The neuronal basis of electrosensory perception and its control of a behavioral response in a weakly electric fish. In Sensory Biology of Aquatic Antmals (ed. J. Atema, R. R. Fay, A. N. Popper and W. N. Tavolga), pp. 851-868. Berlin: SpringerVerlag. 
Helligenderg, W. and Altes, R. A. (1978). Phase sensitivity in electroreception. Science 199, 1001-1004.

HopkINs, C. D. (1976). Stimulus filtering and electroreception: tuberous electroreceptors in three species of gymnotoid fish. J. comp. Physiol. 111, 171-207.

Hopkins, C. D. AND Bass, A. H. (1981). Temporal coding of species recognition signals in an electric fish. Science 212, 85-87.

KNUDSEN, E. I. (1974). Behavioral thresholds to electric signals in high frequency electric fish. J. comp. Physiol. 91, 333-353.

KrAMER, B. (1985). Jamming avoidance in the electric fish Eigenmannia: harmonic analysis of sexually dimorphic waves. J. exp. Biol. 119, 41-69.

Kramer, B. (1987). The sexually dimorphic jamming avoidance response in the electric fish Eigenmannia (Teleostei, Gymnotiformes). J. exp. Biol. 130, 39-62.

Kramer, B. (1990a). Sexual signals in electric fishes. Trends Ecol. Evol. 5, 247-250.

Kramer, B. (1990b). Electrocommunication in Teleost Fishes. Behavior and Experiments. Berlin: Springer-Verlag.

Kramer, B., Kirschbaum, F. and Markl, H. (1981). Species specificity of electric organ discharges in a sympatric group of gymnotoid fish from Manaus (Amazonas). In Sensory Physiology of Aquatic Lower Vertebrates. Adv. physiol. Sci. 31 (ed. T. Szabo and G. Czeh), Pp. 195-219. Budapest: Pergamon Press/Akademiai Kiado.

Kramer, B. AND OTto, B. (1988). Female discharges are more electrifying: spontaneous preference in the electric fish, Eigenmannia. Behav. Ecol. Sociobiol. 23, 55-60.

Kramer, B. and Weymann, D. (1987). A microprocessor system for the digital synthesis of pulsed or continuous discharges of electric fish (or animal vocalizations). Behav. Brain Res. $23,167-174$.

Kramer, B. and Zupanc, G. K. H. (1986). Conditioned discrimination of electric waves differing only in form and harmonic content in the electric fish, Eigenmannia. Naturwissenschaften 73, 679-680.

Lissmann, H. W. (1958). On the function and evolution of electric organs in fish. J. exp. Biol. 35, 156-191.

Rose, G. and Heiligenberg, W. (1985). Temporal hyperacuity in the electric sense of fish. Nature 318, 178-180.

ScheIcH, H. (1974). Neural analysis of waveform in the time domain: midbrain units in electric fish during social behavior. Science 185, 365-367.

ScHeich, H. (1977a). Neural basis of communication in the high frequency electric fish, Eigenmannia virescens (jamming avoidance response). I. Open loop experiments and the time domain concept of signal analysis. J. comp. Physiol. 113, 181-206.

Scheich, H. (1977b). Neural basis of communication in the high frequency electric fish, Eigenmannia virescens (jamming avoidance response). II. Jammed electroreceptor neurons in the lateral line nerve. J. comp. Physiol. 113, 207-227.

Scheich, H. $(1977$ c). Neural basis of communication in the high frequency electric fish, Eigenmannia virescens (jamming avoidance response). III. Central integration in the sensory pathway and control of the pacemaker. J. comp. Physiol. 113, 229-255.

SCHEICH, H. AND Bullock, T. H. (1974). The detection of electric fields from electric organs. In Handbook of Sensory Physiology, vol. II//3 (ed. A. Fessard), pp. 201-256. Berlin: SpringerVerlag.

Scheich, H., Bullock, T. H. and Hamstra, R. H., JR (1973). Coding properties of two classes of afferent nerve fibers: high frequency electroreceptors in the electric fish, Eigenmannia. J. Neurophysiol. 36, 39-60.

SIEGEL, S. (1956). Nonparametric Statistics for the Behavioral Sciences. New York: McGrawHill.

SzaBo, T. (1967). Activity of peripheral and central neurons involved in electroreception. In Lateral Line Detectors (ed. P. Cahn), pp. 295-311. Bloomington (Indiana): Indiana University Press.

Szabo, T. and Fessard, A. (1974). Phýsiology of electroreceptors. In Handbook of Sensory Physiology, vol. III/3 (ed. A. Fessard), pp. 59-124. Berlin: Springer-Verlag.

WATANABE, A. AND TAKEDA, K. (1963). The change of discharge frequency by a.c. stimulus in a weak electric fish. J. exp. Biol. 40, 57-66. 
Westby, G. W. M. (1974). Assessment of the signal value of certain discharge patterns in the electric fish, Gymnotus carapo, by means of playback. J. comp. Physiol. 92, 327-341.

ZAKON, H. H. (1986). The electroreceptive periphery. In Electroreception (ed. T. H. Bullock and W. Heiligenberg), pp. 103-156. New York: John Wiley \& Sons, Inc.

ZAKON, H. H. (1988). The electroreceptors: diversity in structure and function. In Sensory Biology of Aquatic Animals (ed. J. Atema, R. R. Fay, A. N. Popper and W. N. Tavolga), pp. 813-850. Berlin: Springer-Verlag. 